\title{
Hermenêutica e historicidade em António Vieira
}

\section{Leonel Ribeiro dos Suntos}

Constitui um dos pontos mais característicos da concepção henmenêutica vieiriana a insistência no papel que o tempo desempenha no processo do desenvolvimento e revelação da verdade, o que é dito na recorrente tese segundo a qual «o melhor comentador das profecias é o tempo». Tal tese supõe a introdução do tempo na substância da verdade. E o que mais surpreende é que ela não se refere apenas às verdades humanas e mundanas, mas também, e antes de mais, às verdades teológicas e até mesmo às verdades reveladas nas Escrituras Sagradas. Há um real crescimento da verdade, pelo menos do ponto de vista da sua manifestação aos homens ou da consciência que estes dela alcançam. Esta tese de Vieira constitui sem dúvida uma das mais prístinas formulações da íntima correlação que existe entre hermenêutica e historicidade, segundo a qual toda a interpretação é possibilitada e ao mesmo tempo limitada pelo respectivo horizonte histórico do intérprete.

O tema não é novo de todo e o próprio Vieira, nas suas Respostas aos Inquisidores, refere que essa sentença se encontra já nos antigos Padres ${ }^{3}$. Ele é frequentemente glosado com maior ou menor extensão e em muito diversificados contextos na literatura seiscentista, nomeadamente na literatura hispânica ${ }^{2}$. Mas o que verdadeiramente surpreende é a tão clara assunção desse princípio num contexto de verdade teológica. A versão mais antiga deste tópico encontra-se na poeta latino Aulo Gélio, que a atribui a um não nomeado poeta antigo, sob a fórmula - veritas temporis filia ${ }^{3}$. O tópico só viria, porém, a acançar plena expressão na aurora do pensamento moderno, ao ser explicitado, como tradução da própria visão moderna da história e do progresso do conhecimento humano, nos escritos de Francis Bacon ${ }^{4}$. Tirando este filósofo inglês,

1 Defesa do Livro intitulado "Quinto Império» que é a apologia do livro "Clavis Prophetarum» e respostas das proposições censuradas pelos Inquisidores, estando recluso nos cárceres do Santo Ofício de Coimbra (1666), in P.e António Vieira, Obras Escolhidas, Prefácios e notas de António Sérgio e Hernâni Cidade, Livraria Sá da Costa Editora, Lisboa, 1952, Vol.VI, p. 157.

2 Como mostrou José Antonio Maravall, Antiguos y Modernos. Visión de la historia e idea de progreso hasta el Renacimiento, Alianza Editorial, Madrid, 1986, pp. 586 ss. Não é impossível que Vieira se tenha familiarizado com o tema através da literatura hispânica, nomeadamente do Criticón de Baltasar Gracián. Mas em nenhum dos autores aduzidos por Maravall o tópico ganha a dimensão que têm nos escritos de Vieira, os quais, todavia, o historiador das ideias castelhano não cita.

3 Aulus Gelius, Noctes Atticae, lib.xii, cap. 11: «Alius quidam veterum poetarum, cujus nomen mihi nunc memoriae non est, veritatem temporis filiam esse dixit». O poeta antigo poderá bem ser Sófocles, em cuja tragédia Ajax (647-648) se lê: «É o ingente e incontável tempo que faz ser todas as coisas não manifestas e que esconde as que apareceram».

4 Francis Bacon, Novum Orgamum (1620), Lib.I, 84 (The Works of F.B., ed. Speding/Ellis/ Heath, London, 1858, Vol. I, p. 191): «Recte enim Veritas Temporis filia dicitur, non Authoritatis». 
não conhecemos, no contexto do pensamento do século XVII, quem, para além do jesuita português, tenha feito tão amplo e consequente desenvolvimento desse motivo. Os capítulos 10-12 do seu Livro Anteprimeiro da História do Futuro são um verdadeiro manifesto da consciência moderna da história e da própria historicidade do conhecimento e da verdade, dignos de figurar numa antologia de Manifestos da Modernidade.

Vieira dá-nos, de facto e com antecipação de mais de duas décadas em relação à célebre Querelle des Anciens et des Modernes (1688) de Charles Perrault, uma pesșoal e singular versão teológica da "controvérsia disputada entre as cousas novas e as velhas $»^{5}$, uma controvérsia que na verdade o é de todos os tempos, pois, como ele mesmo o diz, «todos os grandes engenhos tiveram sempre esta queixa... porque todos disseram cousas novas, e nenhum careceu de quem lhas impugnasse ${ }^{6}$, mas que na época, como é sabido, constituíu uma querela que concitava e mobilizava os intelectuais e a propósito da qual se decidiam divergentes estratégias e modelos culturais. Evidentemente, Vieira não considera que o mero atributo da novidade constitua acreditação bastante da verdade ou da bondade de uma interpretação. O que de todo rejeita é o preconceito segundo o qual só a antiguidade merece crédito. Daí a tese que defende no capítulo undécimo da referida obra: «as cousas novas, por novas, não desmerecem o crédito de sua verdade» ${ }^{7}$. Na sua argumentação, parecendo contradizer o que antes defendera, o pensador jesuíta vai proceder à própria anulação do conceito de antiguidade e do preconceito da sua maior valia, declarando: «Não é o tempo, senão a razão, a que dá o crédito e autoridade aos escritos, nem se deve perguntar quando se escreveram, senão quão bem. A antiguidade das obras é um acidente extrínseco, que nem tira nem acrescenta qualidade, e só porque põe os autores delas mais longe dos olhos da inveja, lhes granjeia a triste fortuna de serem mais venerados ou melhor conhecidos depois da morte que enquanto vivos» ${ }^{8}$.

Num outro passo, Vieira invoca a distinção entre a verdade considerada em si mesma e o processo da sua aquisição pelo homem. Propriamente falando, não é em relação à verdade mas em relação ao conhecimento dela que o tempo exerce a sua jurisdição: «A verdade e as ciências, em que não tem jurisdição o tempo, impropriamente se chamam novas ou velhas, porque sempre são, sempre foram e sempre hão-de ser as mesmas, posto que não sempre se conhecessem igualmente» ${ }^{9}$.

Por fim, seguindo também neste ponto uma estratégia análoga daquela que antes dele haviam seguido alguns dos mais destacados pioneiros da Modernidade - Giordano Bruno $^{10}$, Francis Bacon ${ }^{11}$ e Thomas Hobbes ${ }^{12}$-, na sua luta contra o comum preconceito

5 Padre António Vieira, Livro Anteprimeiro da História do Futuro, ed. crít. de José van den Besselaar, Biblioteca Nacional, Lisboa,1983, p. 123. Como o faz notar Vieira, esta querela é de todos os tempos, embora na sua época ela tenha sido agudizada ao extremo, como estratégia de demarcação do paradigma renascentista, no qual se privilegiava não só o regresso aos Antigos como também a imitação destes. Todavia, também já no Renascimento se pode acompanhar essa mesma controvérsia. Veja-se: Hans Baron, «The Querelle of the Ancients and Moderns as a Problem for Renaissance Scholarship», in P. O. Kristeller and P. P.Wiener (eds.), Renaissance Essays, New York, 1968, pp. 95-114. Para uma perspectiva sobre a "Querelle» e seu significado, veja-se: Jochen Schlobach, Zyklentheorie und Epochenmetaphoriik. Studien zur bildlichen Sprache der Geschichtsreflexion in Frankreich von der Renaissance bis zur Frühaufklärung, W. Fink, München, 1980, pp. 226-303.

6 Livro Anteprimeiro, p. 121.

7 Ibidem, p. 115.

8 Ibidem, pp. 116-117.

9 Ibidem, p. 123.

10 La Cena delle ceneri (1584), ed. de G. Aquilecchia, Einaudi, Torino, 1955, p. 106: «Bene maestro Prudenzio si questa volgare, et vostra opinione per tanto è vera, in quanto che è antica: certo era falsa quando la fu nova [...] Poniamo dumque da canto la raggione de l'antico et novo; atteso che non è cosa nova, che non possa esser vecchia: et non è cosa vecchia, che non sii stata nova...».

11 Ibidem: «De antiquitate autem opinio, quam homines de ipsa fovent, negligens omnino est, et vix verbo ipsi congrua. Mundi enim senium et grandaevitas pro antiquitate vere habenda sunt; 
a favor dos antigos sobre os modernos, o pensador português opera a inversão de valor entre antiguidade e modernidade, nestes termos: «Todos dizem que os Antigos merecem maior louvor, e é assim, mas este louvor, se bem se considera, não é elogio da antiguidade, senão da novidade. Merecem maior louvor os Antigos, porque foram os primeiros inventores das cousas: logo da novidade é o louvor, pois mereceram, quando as descobriram de novo» ${ }^{13}$.

Num outro passo, Vieira é ainda mais explícito na sua ideia, expondo o seu pensamento ao fio da metáfora biológica, comparando as idades da história com as idades do homem, e concluindo que, de acordo com a ordem da natureza, são mais sábios os modernos do que os antigos, pois são aqueles e não estes os que têm mais idade, por se encontrarem na fase mais madura da história. Nas palavras do pensador barroco português: «De sorte que vai crescendo a inteligência, a ciência e a sabedoria pelos mesmos graus do tempo em que vão crescendo e passando os anos, os séculos e as idades; e isto não só na Igreja universal e em comum, senão nos homens e doutores particulares, que são os membros de que o seu corpo, e os raios de que a sua luz se compõe. Donde se deve reparar e advertir (cousa que devera estar já muito notada e advertida) que os autores antigos e mais velhos, própria e rigorosamente falando, não são os passados, senão os presentes; não aqueles que vulgarmente são chamados os Antigos, senão os que hoje e nos tempos mais chegados a nós se chamam Modernos... Donde se segue que os doutores da infância, da puerícia e adolescência da Igreja foram os modernos e da ciência moderna; e os doutores da idade maior e mais provecta da Igreja são os mais velhos e mais antigos e da ciência mais antiga; porque a Igreja não se compõe das paredes mortas, senão dos membros vivos; nem foi crescendo dos nossos anos para os primeiros, senão dos primeiros para os nossos. E seria não só contra a ordem da natureza, senão contra a decência da mesma idade, que não fosse mais sábia a Igreja nos maiores anos do que o tinha sido nos primeiros $\rangle^{14}$.

$\mathrm{O}$ jesuíta português tem, por conseguinte, uma arreigada concepção do conhecimento humano como um processo em crescimento. E se isso vale para o «grande oceano das ciências humanas», mais vale ainda para o «abismo sem fundo das ciências divinas ${ }^{15}$. Em plena sintonia com alguns dos mais ilustres representantes da nova consciência moderna do tempo, que não só não sacralizavam os antigos e as suas posições, mas os compreendiam nos limites e condições do seu tempo, e lhes preferiam os pensadores modernos ou mais recentes, por traduzirem melhor a maturidade dos tempos e do próprio mundo, Vieira pergunta: «Porque havemos nós de desprezar e afrontar tanto a nossa idade e os homens dela, que cuidemos que já não podem adiantar as ciências, nem dizer e acrescentar sobre elas cousas de novo?... Muito alcançaram os Antigos, ... mas ainda nos deixaram seus grandes talentos em que exercitar os nossos» ${ }^{16}$.

A partir deste ponto, pode compreender-se melhor o modo como Vieira entende a tradição e a fidelidade à tradição. Não como uma herança morta que se recebe, conserva

quae temporibus nostris tribui debent, non juniori aetati mundi, qualius apud antiquos fuit. Illa enim aetas, respectu nostri, antiqua et major; respectu mundi ipsius, nova et minor fuit. Atque revera quemadmodum majorem rerum humanarum notitiam et maturius judicium ab homine sene expectamus quam a juvene, propter experientiam et rerum, quas vidit, et audivit, et cogitavit, varietatem et copiam; eodem modo et a nostra aetate (si vires suas nosset, et experiri et intendere vellet) majora multo quam a priscis temporibus expectari par est; utpote aetate mundi grandiore, et infinitis experimentis et observationibus aucta et cumulatan.

12 The English Works of Thomas Hobbes, ed. Molesworth, London, 1839, Vol. I, p. 456): «I honour antiquity; but that which is commonly called old time is young tjme. The glory of antiquity is due, not to the dead but to the aged».

13 Livro Anteprimeiro, ed. cit., p. 124.

14 Ibidem, p. 131. Sobre o uso da metafórica das idades do homem nas filosofias (e teologias) da história da época moderna, veja-se: Alexander Demandt, Metaphern für Geschichte. Sprachbilder und Gleichnisse im historisch-politischen Denken, Beck, München, 1978.

is Livro Anteprimeiro, pp. 107-108.

16 Livro Anteprimeiro, ed. cit., p. 118. 
e repete, mas como um património que se desenvolve e continuamente se acrescenta, mediante novos inventos do entendimento e engenho próprios de cada intérprete. Mas, por outro lado, o trabalho dos últimos intérpretes inscreve-se no esforço dos seus predecessores, e se aqueles vêem mais e melhor é só porque gerações de intérpretes, por entre tentativas e névoas, lhes abriram o caminho. Retomando, sem mencionar a sua proveniência, uma sentença que João de Salisbúria atribuíra ao seu mestre Bernardo de Chartres, Vieira considera os intérpretes mais modernos como pigmeus às costas de gigantes: «Pigmeus nos reconhecemos em comparação daqueles gigantes que olharam antes de nós para as mesmas Escrituras. Eles sem nós viram muito mais do que nós pudéramos ver sem eles, mas nós, como viemos depois deles e sobre eles pelo benefício do tempo, vemos hoje o que eles viram e um pouco mais. O último degrau da escada não é maior que os outros, antes pode ser menor; mas basta ser o último e estar em cima dos demais, para que dele se possa alcançar o que dos outros se não alcançava» ${ }^{17}$.

Na mesma linha, glosando a parábola evangélica dos cavadores da vinha, os quais, tendo sido contratados na última hora, fizeram o que os outros não haviam feito em todo o dia, escreve o autor da História do Futuro: «Os que estudamos e trabalhamos na inteligência da Sagrada Escritura, mais ou menos todos cavamos, e pode suceder que os que vêm na última hora, por felicidade da mesma hora, acabem e descubram com poucas enxadadas o que muitos em muito tempo e com muito trabalho, cavando muito mais, não descobriramı ${ }^{18}$.

Na Clavis, o adiantado dos tempos da história contemporânea é apresentado como uma razão de vantagem para aquele que quer perscrutar os sinais do fim do mundo, pois é certo que esse está muito mais próximo dele do que o estiveram os antigos, os quais todavia não se coibiram de conjecturar a seu respeito. Se aos antigos foi permitido, e se até se enganaram, por que não lhe há-de ser permitido a ele, «e tanto mais ou muitíssimo mais, decorridos tantos séculos, quanto muito mais próximos estamos do fim e podemos observar o futuro mais de perto, mais claramente ou menos obscuramente; o próprio tempo nos ajuda indo adiante de archote em punho, ele que é o melhor intérprete das profecias $)^{19}$.

Já se vê que a ventura dos que chegam na última hora não os autoriza a desconsiderar o trabalho dos das primeiras horas. Vieira reconhece a extraordinária importância que tem para a inteligência do texto sagrado não só a história das suas interpretações como também a própria controvérsia ou a diferença de opiniões. O consenso dos espíritos - assim parece depreender-se das teses do Padre Vieira - não deve ser conseguido à custa da perda da liberdade individual de investigação, por certo esclarecida e responsável. Se ele faz questão de mencionar aos seus juízes inquisidores a sua ocupação de 40 anos com os textos da Escritura e seus mais autorizados comentadores, desde os mais antigos Padres até aos mais recentes teólogos, não é por certo para exibir a autoridade da sua erudição, mas por acreditar que é com o longo e aturado estudo de muitas disciplinas que o intérprete se prepara para a sua função. Em última instância, porém, a dispensação da revelação e da sua interpretação (pois também a interpretação da palavra revelada faz parte da revelação), obedece a uma ordem temporal, segundo uma economia da divina Providência. Pelo que não alcança a inteligência do sentido genuíno das Escrituras quem quer ou quem apenas possui alto engenho e estudo, mas aquele que chega «na hora determinada por Deus» ${ }^{20}$.

Estamos perante um aspecto essencial do pensamento de Vieira - a sua concepção de que tudo no mundo espiritual e político obedece a um plano da sabedoria e providência de Deus, que só paulatinamente nos vai sendo dado perceber. Nesse espaço entre o

17 Livro Anteprimeiro, p. 106. Sobre a origem e transmissão desta imagem, veja-se: Maravall, ob. cit., pp. 232 ss.

18 Ibidem.

19 Ibidem, p. 112.

20 Ibidem, p. 108. 
algo que já se percebe e o muito que ainda permanece oculto encontra o homem um motivo para admirar a majestade da sabedoria e omnipotência divinas na divina comédia que Deus leva à cena do Mundo com os homens, actores e espectadores de uma peça de que não são, porém, os verdadeiros autores. Para expor esta concepção, Vieira socorre-se de uma metáfora, recorrente nos seus textos e igualmente característica da mundividência barroca - a metáfora do teatro -, na qual se condensa, numa admirável economia, toda a sua filosofia e teologia da história. Demos-lhe a palavra: «Este mundo é um teatro, os homens as figuras que nele representam, e a história verdadeira de seus sucessos uma comédia de Deus, traçada e disposta maravilhosamente pelas idades de sua Providência. E assim como o primor e subtileza da arte cómica consiste principalmente naquela suspensão do entendimento e doce enleio dos sentidos, com que o enredo os vai levando após si, pendentes sempre de um sucesso para outro sucesso, encobrindo-se de indústria o fim da história, sem que se possa entender onde ir parar, senão quando já vai chegando e se descobre subitamente entre a expectação e o aplauso; assim Deus, soberano Autor e Governador do Mundo, e perfeitíssimo Exemplar de toda a natureza e arte, para maior manifestação de sua glória e admiração de sua sabedoria, de tal maneira nos encobre as cousas futuras, ainda quando as manda escrever pelos profetas, que nos não deixa compreender nem alcançar os segredos de seus intentos, senão quando já têm chegado ou vão chegando os fins deles, para nos ter sempre suspensos na expectação e pendentes de sua Providência» ${ }^{21}$.

Tal como o apóstolo Paulo, também Vieira considera que o espírito profético está disseminado por todo o povo de Deus. O profeta, o intérprete das profecias e o pregador são aqueles que estão mais particularmente dotados para ler os sinais dos tempos e perceber não só o sentido em que se encaminha a história, mas também para perceber como e quando se aproxima o seu termo. Por conseguinte, o pregador não exorbita da sua função quando interpreta as profecias e até quando ele próprio profetiza. Como escreve o jesuíta português, os pregadores são «os intérpretes da mesma voz de Deus» ${ }^{22}$. Não excede o seu múnus quando pretende inscrever eficazmente nos acontecimentos o supremo sentido que entende presidir-lhes. Pregador, ele é assim simultaneamente historiador e profeta. Há ocasiões em que o orador barroco explicita essa acumulação de funções, como para reforçar retórica e realmente a eficácia do sermão. Eis um desses casos: «É tão particular história a que hoje nos refere S. Lucas no cap. 24 da sua [trata-se do episódio dos discípulos de Emaús - tristes por terem sido defraudadas as suas espectativas...], que contra o estilo que ordinariamente costumo seguir, quero... que seja o sermão a mesma história. Historiador e pregador hei-de ser hoje: dobrada obrigação de dizer verdades. [...] O que me parece posso prometer seguramente é que a história vos não enfastie por antiga e mui sabida; porque, ainda que segundo a boa cronologia, é de mais de mil e seiscentos anos, eu farei que pareça a história de nossos tempos. Nenhuma cousa ouvireis que não seja o que vedes $»^{23}$.

O sermão em causa é uma crítica dura, mas cheia de ironia, ao modo como eram distribuídas as mercês reais a vassalos sempre descontentes e que as não mereciam por seus reais feitos. No final, conclui o nosso orador: «Prometi fazer neste sermão um juízo dos anos que vêm, e eu não fiz mais que referir os sucessos dos anos passados. Mostrei a razão das profecias, as dilações da esperança, o acerto dos decretos [...] e tudo isto é história do que foi, e não prognóstico do que há-de ser. Ora, ainda que o não pareça, eu me tenho desempenhado do que prometi, e todo este discurso foi um prognóstico certo e um juízo infalível dos anos que vêm. Tudo o que disse, ou foram profecias cumpridas, ou benefícios manifestos da mão de Deus; e em profecias e

21 Ibidem, p. 110.

22 Obras escolhidas, Vol. VII, p. 50.

23 Sermão da 1. a oitava da Páscoa (1647), in Padre António Vieira, Obras Completas, Sermões, Lello \& Irmão, Porto, 1959, Vol. II, p. 195. 
benefícios começados, o mesmo é referir o passado, que prognosticar e segurar o futuro $[. .$.$] porque os efeitos presentes dos passados são nova profecia dos futuros» { }^{24}$. Não só nos seus Sermões mas ainda mais nos seus escritos de hermenêutica das profecias, com destaque para a Clavis, Vieira pratica ao limite aquilo a que Fernando Gil chamou a «fusão dos tempos», pois na realidade é como se, para ele, tudo se passasse dentro de um mesmo e único tempo, em que as distinções de passado, presente e futuro são intercomunicáveis e ao limite se dissolvem ${ }^{25}$. Mas se há momento do tempo que seja decisivo para Vieira, esse não é o passado nem o presente, mas sim o futuro, e nisto se pode ler uma característica dimensão da mundividência barroca e moderna do escritor jesuíta: o futuro é o tempo da realização, da plenitude, da consumação. Só desde a perspectiva do futuro se deixa ler e interpretar em toda a sua plenitude e magnificência o plano de Deus levado à cena no palco do mundo e nos actos da história. É por isso também que aqueles intérpretes que estão mais próximos do futuro - isto é, da realização das coisas reveladas ou profetizadas - têm vantagem sobre os intérpretes mais antigos. É precisamente o ponto de vista do futuro que permite compreender a tese vieiriana, que acima comentámos, segundo a qual «o melhor comentador das profecias é o tempo ${ }^{26}$. Pode, por isso, este singular historiador propor-se escrever uma «história do futuro», ou dar «a cópia antes do original». Pois, tal como na visão profética do passado se inclui, como numa intuição única, a realização futura do profetizado, como sendo duas faces de uma e mesma coisa, assim na visão do intérprete, que está mais chegado ao futuro, se deixa decifrar melhor o sentido do profetizado. Pode igualmente o escritor jesuíta, indo contra o procedimento comum dos intérpretes que antes dele haviam sondado a cronologia do fim dos tempos, subverter a ordem da história e ler o cômputo dos tempos do fim para o começo, do futuro para o passado ${ }^{27}$.

Característico de Vieira é o investimento histórico-político - numa aplicação directa e literal - da sua interpretação da Escritura, em particular das profecias. Mas o jesuíta português não é a esse respeito e no seu tempo um caso isolado. Bem pelo contrário. Aliás, se a própria Escritura não é ela mesma senão a revelação de um sentido messiânico inscrito nos acontecimentos da história política do povo judaico, como não transportar esse sentido para os acontecimentos e factos da história actual e futura, sendo que o supremo autor e condutor da história, aquele que lhe garante o seu sentido e a leva à plenitude da sua realização, é o mesmo Deus que se revelou outrora aos profetas e escritores bíblicos, para quem todos os momentos do tempo são um mesmo Presente e «os futuros são presentes»? De resto, a técnica da aplicação moral do sentido do texto à vida e da aplicação tipológica e literal da profecia à decifração do sentido dos

24

25

26

Sobre a «temporalização da história» que se dá no início da Modernidade e a importância que nela passa a desempenhar a categoria do «futuro» como factor de respectiva realização e aceleração, veja-se: Reinhart Koselleck, Vergangene Zukunft. Zur Semantik geschichtlicher Zeiten, Suhrkamp, Frankfurt a.M., 1979. Embora nunca cite (e nem porventura conhecesse) a História do Futuro do Padre Vieira, Koselleck podia bem encontrar representado nos escritos de Vieira (e não com menor eloquência do que o vê no quadro de Albrecht Altdorfer, «A Batalha de Alexandre»), todo o curso da história, mas lido preferentemente desde o seu desfecho final, ou desde o seu futuro. Veja-se o nosso ensaio «Melancolia e Apocalipse. Vivência do tempo e concepção da história em António Vieira», in Cristina Almeida Ribeiro, Maria João Brilhante, Paula Morão e Teresa Amado (orgs.), Letras, Sinais. Para David Mourão-Ferreira, Margarida Vieira Mendes e Osório Mateus, Edições Cosmos, Lisboa, 1999, pp. 363-373.

27 Padre António Vieira, Clavis Prophetarum/Chave dos Profetas, Livro III, ed. crítica e trad. de Arnaldo Espírito Santo, Biblioteca Nacional, 2000, pp. 75-77. 
acontecimentos da história política presente ou futura era um procedimento característico da própria Escritura. Alguns acontecimentos e pessoas são investidos de uma especial potência de significação, como tipos ou figuras de outros acontecimentos ou personagens futuros, gerando-se uma fecunda permuta semântica entre o tipo e o tipificado, entre a figura e o figurado (Adão-Cristo, Israel-Igreja). Paulo fez larguíssimo uso desse procedimento exegético ${ }^{28}$.

Para Vieira, interpretar a profecia é desvendar e criar o sentido da história, é intervir na história de forma criativa, moldando-a. O comprometimento pessoal e até passional do escritor e pregador é bem consciente, como o denuncia, entre muitas outras possíveis, esta sua observação: «Que historiador houve de tão limpo coração e tão inteiro amador da verdade, que o não inclinasse o respeito, a lisonja, a vingança, o ódio, o amor, ou da sua ou da alheia nação, ou do seu ou do estranho príncipe? Todas as penas nasceram em carne e sangue, e todos na tinta de escrever misturam as cores do seu afecto» ${ }^{29}$.

Tal como outrora os profetas bíblicos, ao profetizarem o futuro, intervinham efectivamente na história presente do povo hebreu, assim agora o pregador e hermeneuta intervém na consumação da história, proporcionando aos seus leitores e ouvintes «um espelho em que vejam os futuros» e assim, pelo conhecimento dos futuros, emendem o engano de suas esperanças presentes ${ }^{30}$.

Vieira pratica uma história e uma hermenêutica interessadas, uma interpretação das profecias ao serviço da história que se deseja e uma história do futuro ao serviço da esperança - da expectativa e da urgência - do presente. Hermeneuta da história e do seu sentido, ele não é um mero espectador desinteressado do curso da história, mas sim, e por isso mesmo, um participante e um actor qualificado dessa história cujo sentido decifra e anuncia ${ }^{31}$. Não se compreende o pensamento messiânico de Vieira sem as bases da antropologia e psicologia social que a suportam, uma antropologia e psicologia que são regidas pela poderosa economia do desejo duma razão moralmente interessada na efectiva realização de tudo o que se prometia na figura do «reino messiânico». A profecia é o alimento do desejo e da esperança e, por isso, o escritor bíblico podia dizer que «morre o povo onde deixa de haver profetas»" ${ }^{32}$. Mas o pensador barroco sabe também que o desejo e a esperança não se satisfazem com promessas adiadas para os indeterminados horizontes do longínquo futuro, mas urgem a sua realização e

28 Veja-se: Jean Daniélou, Sacramentum Futuri. Études sur les origines de la typologie biblique, Paris, 1950.

29 Livro Anteprimeiro, p. 101. Caberia aqui uma referência ao peculiar patriotismo de Vieira e à sua tenaz fé no destino histórico e messiânico de Portugal, mesmo contra todas as evidências. Veja-se, como documento-confissão dessa incurável paixão, tão extremamente lúcida quão penosamente sofrida, a carta de Vieira a Duarte Ribeiro de Macedo, de 17 de Outubro de 1673, in Cartas do Padre António Vieira, coordenadas e anotadas por J. Lúcio de Azevedo, Imprensa Nacional, Lisboa, 1971, Vol. II, pp. 646-647.

30 Livro Anteprimeiro, pp. 77-78.

31 Esta interessada hermenêutica vieiriana da história não deixa de ter alguma analogia com a situação em que, um século mais tarde, se reconhece o filósofo moral Immanuel Kant quando, em presença de um acontecimento da história política contemporânea como era a Revolução Francesa, não se coibe de tentar decifrar como ele se inscreve no sentido da história humana e assim lê esse acontecimento como um sinal histórico (Geschichtszeichen) que indica uma inequívoca "disposição moral existente no género humano» (moralische Anlage im Menschengeschlecht) para progredir moralmente para o melhor (Fortschreiten zum Besseren), e essa disposição manifesta-se como uma «tendência moral» (moralische Tendenz) que leva os espíritos a terem nesse acontecimentos «uma participação segundo o desejo, que confina com o entusiasmo» (eine Teilnehmung dem Wunsche nach, die nahe an Enthusiasm grenzt). Immanuel Kant, Streit der Fakultäten, Akademie Ausgabe, Bd.VII, 84-85. Este aspecto do pensamento kantiano foi particularmente destacado, por Jean-François Lyotard, na obra: L'enthousiasme. La critique kantienne de l'histoire, Éditions Galilée, Paris, 1986. 
consumação próximas. Por isso o autor desse singular género de história-profecia que é a «história do futuro» anuncia «grandes futuros ao desejo», assegura «breves desejos ao futuro», promete um «futuro que brevemente há-de ser presente», pois sabe que «ainda que seja muito segura, muito firme e muito bem fundada a esperança, é um tormento desesperado o esperar» ${ }^{33}$. 